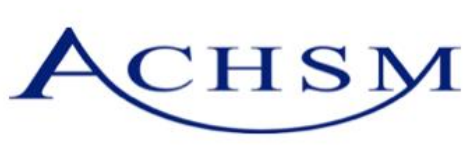

\title{
IMPROVEMENT OF ELDERLY HEALTH CARE VOUCHER SCHEME IN HONG KONG
}

\author{
Cheryl C. W. Hol, Tommy K. C. Ngl \\ 1. School of Professional Education and Executive Development, The Hong Kong Polytechnic University
}

Correspondence: speed18037204@gmail.com

\section{ABSTRACT}

Elderly Health Care Voucher Scheme is a financial support provided by the government to the elderly for having more choices in selecting private primary health care services. It has been launched for more than ten years (including pilot scheme). The success of the voucher depends on its effectiveness so that Hong Kong elderly can benefit from it. The aim of this article is to analyse whether the voucher scheme has achieved its goals and what improvement can be made. The scheme is successful in encouraging the elderly to use private primary care, considering that the participation rate of the scheme is high, and elderly could use private health care services to supplement public health care services. Yet, the amount of the subsidy is insufficient to support the needs of the elderly and the providers of the voucher are not enough for Hong Kong elderly. Also, it is found that private health care services give the old generation an impression of expensiveness and unreliable even with the support of the Health Care Voucher. To improve the Elderly Health Care Voucher Scheme and solve the problems, the government should increase the amount of the voucher, set standards for regular monitoring, cooperate with private health care providers and invite more providers. Ultimately, the elderly would enjoy greater flexibility in choosing medical services in meeting their needs and the scheme can effectively achieve its purpose.

\section{KEYWORDS}

elderly health care, voucher scheme, primary care, private health care services

\section{INTRODUCTION}

The ageing population is rising in Hong Kong and will rise from 116 million in 2016 to 237 million in 2036. [1] In other words, the elderly accounting for the overall population will increase almost double from $16.6 \%$ to $31.1 \%$ in the same period. It is foreseeable that the spending on elderly health care will increase. To deal with the ageing population, the Hong Kong Government has launched the Elderly Health Care Voucher Scheme (the Scheme) to encourage the elderly to utilise private primary care instead of public health service. The aim of this study is to analyse the effectiveness of the health voucher scheme and provide suggestions for improvement.

\section{HONG KONG ELDERLY HEALTH CARE VOUCHER SCHEME}

The Elderly Health Care Voucher is a subsidy provided by the Hong Kong Government for the elder adults to select private primary health care services. [2] It aims to allow the elderly to choose the most suitable private medical services with financial incentives to support current private health care services and improve primary care for the elderly. The scheme encourages the elderly to establish a closer relationship with private doctors who will become familiar with their health situation and promotes the concept of family doctors. The scheme was launched in 2009 as a pilot scheme. Each elderly who was aged 70 or above could obtain five vouchers at HK\$50 each year. Based on the Interim Review in 2011, the Scheme was extended until 2014. [6] After years of operations, the amount of the Elderly Health Care Voucher had been increased to HK\$500 in 
2012, $H K \$ 1,000$ in 2013 and $H K \$ 2,000$ in 2014 a year. In order to increase the flexibility on the utilisation of voucher, the face value was decreased to HK\$1 units in 2014. The Scheme started to allow the amount to be accumulated to an upper limit of $H K \$ 3,000$ since January 2014. The value of the upper limit was soon adjusted to HK\$4,000 in June 2014 and, is now at $\mathrm{HK} \$ 8,000$ since 2019 , with the allowance of $\$ 2,000$ every two years in using on optometric services. In addition, the eligibility age was dropped from 70 to 65 years in 2017 to cover and benefit more elderly.

\section{EVALUATION}

\section{UTILISATION}

The utilisation rate of the Health Care Voucher has risen from $28 \%$ to $78 \%$ between 2009 and 2017. [3] It shows that the Scheme is successful in encouraging the elderly to use private care considering that the participation has increased and most of the elderly has joined the scheme. [3]

The average frequency of each elderly visiting private western medicine trained doctors have increased from 0.62 per year in 2009 to 3.45 per year in 2015, increasing by 5.6 times. [4] For the average frequency of visiting public hospitals, it has only increased from 5.81 per year to 6.38 per year. Thus, the increase of average frequency of visiting private western medicine trained doctors is higher than that of visiting public hospitals. Not only increasing in visiting private doctors, the number of times that elderly using public services has decreased, because the average frequency of public hospital visits of each elderly was 6.65 per year in 2013, 6.47 per year in 2014 and further dropped to 6.38 in 2015. [4] As mentioned, the purpose of the Health Care Voucher is to provide chances for elderly to use private health care services to supplement public health care services. The increase in using private services through the voucher and decrease in using public services has showed the Health Care Voucher achieved this aim.

\section{PREVENTIVE CARE}

The scheme is not effective in promoting preventive care because the increasing trend of the utilisation on preventive care has not matched the participation rate. The percentage of voucher claim transactions on preventive care has risen by only $6 \%$ (from $7 \%$ to $13 \%$ ) from 2009 to 2017. [5] The elderly are unwilling to pay for preventive care in the private services. [6] They prefer to pay for consultations of acute diseases. Likewise, they are fairly satisfied with current public health care system because of the low charges. They also perceive the private health care services expensive even with the support of the vouchers. In their opinion, it is not worth to choose the expensive services when there is "no difference" in the quality of services at public and private hospitals and clinics.

As an objective of the Scheme, the elderly is encouraged to choose primary health care services. Primary health care contains promotion on health, prevention of diseases, treatment, chronic diseases and rehabilitation. [7] From Census and Statistics Department, more than three quarters of people aged 70 years and above suffer from different kinds of chronic diseases. [8] The possibility of suffering from multimorbidity by the elderly seems to be 18 times more than people aged between 14 and 25. [9] In order to avoid the chronic diseases from becoming worse, consultations for preventive measurements should be done earlier in the management of chronic diseases. [9] However, some of the preventive services and medicines for chronic diseases are expensive in the private sector. The voucher amount is not enough to cover the consultation fees and individuals need to pay for the services as well. As the result, the elderly is not willing to see private doctors, especially for diseases which require continual follow-ups. They mainly spend the vouchers for common clinic consultations only. [10] Therefore, the Scheme cannot really achieve the goal of promoting primary care.

\section{CO-OPERATION BETWEEN THE GOVERNMENT AND PRIVATE PROVIDERS}

Unfortunately, complaints about the scheme in its operational procedures, suspected fraud and improper claims, etc., increased from 24 to 72 from 2015 to 2017 respectively. There were totally 235 complaints from 2015 to 2018. [11, 12] Committing frauds and misconducts may lead to the lack of trust between the elderly and the providers. [9] In order to encourage the elderly to use more private services, trust between the user and service provider is the key factor. [13] Therefore, willingness to use the private services may be reduced due to the lack of trust. Wong et al. have recommended that 'high commitment' $(\mathrm{HC})$ mechanisms are useful in changing the behaviour, especially when the government launches a public-private partnership where the patient does not have a strong trust in the private services providers. [13] To maintain a $\mathrm{HC}$, private services providers should be engaged in all stages related to the policy development and launching. Wong et al. have also suggested that the 
private sector should participate more in logistic arrangements. [13] However, private providers in Hong Kong appear to support the programme passively as the government has turned a deaf ear to their concerns, such as the request on technical support. The patient registration process of the Scheme requires an advanced IT system and staff support. Private provides have difficulties in seeking help from the government. Therefore, the current situation is unhealthy in that the commitment level is not high enough and may lead to difficulty in promoting the Scheme. The co-operation and ongoing dialogue between the government and private providers must be strengthened.

\section{GEOGRAPHICAL COVERAGE}

With the development of the Great Bay Area in the Guangdong Province, some Hong Kong elderly may choose to live there for the rest of their life. [14] It is time consuming and costly if these older adults need to come back to Hong Kong to seek medical consultations. In June 2019, the government has increased the coverage of the Scheme. Elderly living in Great Bay Area and holding the Hong Kong Identity card can use the voucher for using private health care services at the Hong Kong UniversityShenzhen Hospital (HKU-SZ Hospital) in Shenzhen, currently the only designated site in the Great Bay Area under the scheme. [2]

\section{RECOMMENDATIONS}

\section{INCREASE THE VOUCHER AMOUNT}

The government should increase the amount of the voucher to meet the needs of the elderly. In this way, the elderly does not have to save and accumulate their vouchers for a few years to prepare for some expensive health care services, such as dental services and optometric services. Thus, they can receive treatment without delay.

\section{PROMOTE THE USE OF PREVENTIVE CARE}

Promotion of preventive care should be enhanced. Chong et al. suggest that the voucher office should work and cooperate with service providers to promote the Scheme for preventive services, through delivering leaflet, holding educational talks and carnival. [10] Then, the elderly can understand more about the importance of preventive care. The government can also promote the preventive care through categorizing the voucher, i.e. classifying the original voucher to general health care voucher and preventive care voucher. $[9,10]$ Lai et al. have proposed to the launch the vouchers for specific purposes as the most effective way. [9] With this arrangement, the kinds of services "cashed" by voucher will be restricted and elderly who do not want to "waste" the preventive care voucher will try to use it. Then, the utilisation rate of health care voucher on preventive care will be expected to increase. Hopefully, the need for hospitalisation will be decreased in the longer term and the quality of life of the old people should be enhanced as a result of better health.

\section{INCREASE TRANSPARENCY OF FEES}

Increasing the transparency of the charges of private health care services to the elderly may increase their willingness to spend more on private services such as preventive care and consultations with the family doctors. If the elder adults do not know the costs of the services, they may be hesitant to use the services because they are concerned about the fees being too high that they could not afford.

\section{INCREASE GEOGRAPHICAL COVERAGE}

The current geographical coverage of the Scheme outside Hong Kong is limited and should be expanded. Expanding the use of vouchers to regions other than Greater Bay Area and the HKU-SZ Hospital can provide even more choices for Hong Kong elderly living in the mainland. [6] Similarly, the elderly should be allowed to use health care services with the vouchers in many more parts of the Mainland since with the support and convenience of the High Speed Rail, which is making the travel so easy. Expanding the coverage of the health care voucher to beyond the Greater Bay Area is indeed a milestone of the Scheme.

Encourage private services providers to join the Scheme To achieve $\mathrm{HC}$, it is necessary to encourage more private services providers to enrol in the Scheme. [9] It will be more convenient for the elderly to have access the private services. In addition, more providers will potentially lead to competition. On the other hand, providers can gain from the increased utilisation of services through positive images among the users, reasonably low fees and high quality. Eventually those providing low quality or offering services with high price will be weeded out "naturally" and as a matter of fact. The elderly will benefit from higher commitment of the private sector and more choice of service providers.

\section{MONITOR THE PERFORMANCE OF SERVICE PROVIDERS}

In order to increase the trust between the elderly and the service providers, quality should be ensured through 
monitoring and, guidelines should be implemented. [9, 10] Even when low quality services are weeded out in the private sector, it does not mean that the elderly will readily trust the private services providers. Currently, the monitoring function by the government is not enough because only $2 \%$ of total claims had been inspected in the years from 2009 to 2018. [6] If more cases have been inspected and more service providers monitored, manipulation of accounts can potentially be prevented. For example, regular checking, attention to abnormal transactions, handle complains etc. should be noted closely by the Voucher Office. [6] Such measures can help to result in increased trust of the elderly and thus increase their willingness to utilise the vouchers on private services. Therefore, the government should implement some measures in the monitoring the performance of providers and checking the administrative processes. [9]

\section{CONCLUSION}

The Scheme has successfully encouraged the elderly to use private primary care and thus helps to reduce some of the burden of public health care services. However, the amount of the vouchers and number of private service providers can be increased to further meet and cater for the needs of the elderly. Unwillingness to pay for the "perceived" expensive private health services, lack of promotion on preventive services, inadequate and ineffective monitoring, and the reliability of private services providers are the reasons that the elderly does not use the voucher on preventive care or private health services as anticipated. Therefore, improvement strategies and measures are recommended to increase the effectiveness and to meet the objectives of the Scheme.

\section{ACKNOWLEDGEMENT}

The work described in this paper was partially supported by a grant from the Research Grants Council of the Hong Kong Special Administrative Region, China (Project Reference No.: UGC/IDS24/18).

\section{REFERENCES}

1. Census and Statistics Department. Hong Kong population projections for 2017-2066. [Internet]. 2017. [cited 22 January 2020]. Available from: https://www.censtatd.gov.hk/press_release/pressRele aseDetail.jsp? charsetID $=1$ \&pressRID $=4200$

2. Health Care Voucher Division, Department of Health. Home Page. [Internet]. 2019. [cited 26 December 2019]. Available from: https://www.hcv.gov.hk/eng/

3. Research Office of Legislative Council Secretariat. Statistical Highlights: Elderly Health Care Voucher Scheme. [Internet]. 2018. [cited 28 December 2019]. Available from: https://www.legco.gov.hk/researchpublications/english/1718issh 14-elderly-health-carevoucher-scheme-20180227-e.pdf

4. The Government of the Hong Kong Special Administrative Region. Health Care Voucher (長者醫療 劵計劃). [Internet]. 2019. [cited 25 January 2020].

Available from:

https://gia.info.gov.hk/general/201903/11/P201903110 0711_305793_1_1552301999406.pdf

5. Food and Health Bureau \& Department of Health. Report on the Review of the Elderly Health Care Voucher Scheme. [Internet]. 2019. [cited 22 January 2020]. Available from:

https://www.hcv.gov.hk/files/pdf/Review_Report_Engli sh.pdf

6. Yee H, Ng T, Choi J, Suen A, Law V. Elderly health care voucher scheme in Hong Kong - effective or not? CAHMR Working Paper Series, The Hong Kong Polytechnic University, College of Professional and Continuing Education, School of Professional Education and Executive Development, Centre for Ageing and Healthcare Management Research. 2019; 1(3). Available from:

http://weblib.cpcepolyu.edu.hk/apps/wps/assets/pdf /cw20190103.pdf

7. World Health Organization. Primary health care. [Internet]. 2020. [cited 23 January 2020]. Available from: https://www.who.int/health-topics/primaryhealth-care\#tab=tab_1

8. Census and Statistics Department. Persons with disabilities and chronic diseases (Special Topics Report No. 62). [Internet] 2014. [cited 28 February 2020]. Available from https:// www.censtatd.gov.hk/hkstat/sub/sp380.jsp?productC ode=FA100059 
9. Lai A, Kuang Z, Yam C, Ayub S, Yeoh E. Vouchers for primary healthcare services in an ageing world? The perspectives of elderly voucher recipients in Hong Kong. Health \& social care in the community. 2017; 26(3), 374-382.

10. Chong K, Fung H, Yeoh E. Improving Hong Kong's Elderly Health Care Voucher Scheme: an overview and update. Hong Kong Medical Journal. 2019; 25(6), 494-496.

11. Chiu P. Hong Kong's health voucher scheme for the elderly has been running for a decade-so why are curbs on usage being imposed and what effect will they have? [Internet]. 2019. [cited 27 February 2020]. Available from https://www.scmp.com/news/hongkong/health-environment/article/3001592/hongkongs-health-voucher-scheme-elderly-has-been

12. The Government of the Hong Kong Special Administrative Region. LCQ8: Elderly Health Care Voucher Scheme. [Internet]. 2018. [cited 9 March 2020]. Available from https://www.info.gov.hk/gia/general/201803/21/P2018 $032100606 . \mathrm{htm}$

13. Wong E, Yeoh E, Chau P, Yam C, Cheung A, Fung H. How shall we examine and learn about public-private partnership (PPPs) in the health sector? Realist evaluation of PPPs in Hong Kong. Social Science \& Medicine. 2015; 147, 261-269.

14. Legislative Council. Healthcare services for Hong Kong people living in Greater Bay Area. [Internet]. 2019. [cited 28 February 2020]. Available from https://www.info.gov.hk/gia/general/201906/05/P2019 0 